\title{
Elías Rubio Marcos, Memorias de Burgos: entre la tierra y la voz, con presentación de Josemi Lorenzo Arribas, Burgos, Editorial Aldecoa, 2015, 262 pp.
}

Existe un cuento oral de difusión pluricultural, el que tiene el título The king and the abbot (El rey y el abad) y el núm. 922 en el catálogo de Aarne-Thompson-Uther, que trata de un rey (o de un obispo) que, deseoso de poner a prueba la inteligencia de un abad, le pide que resuelva tres retorcidos enigmas. El abad se siente incapaz de superar la prueba $\mathrm{y}$, hundido en la depresión, acepta la ayuda de un pastor cuyo rudo e intuitivo ingenio, conectado con lo puro y lo telúrico, descifra sin mayor dificultad las claves de esos tres misterios. Algunas versiones rematan con la destitución del abad y su sustitución por el pastor. Un final seguramente con trampa, porque extraer al pastor de su medio campesino e implantarlo en las instituciones debe de ser, sospechamos, el modo más eficaz de arruinar su inteligencia y su ética naturales.

Está, creo, justificada la comparación del libro que tenemos entre las manos con un cuento en que quien acaba pronunciando el discurso más clarividente —aquí habríamos de hablar de la etnografía más convincente- es el personaje que vive en la posición más retraída; y de su autor, Elías Rubio, con el rústico que toma su singular saber directamente de su entorno natural y humano, ajeno a corrillos y burocracias académicas.

Elías Rubio no tiene el título de etnógrafo ni de antropólogo ni de filólogo ni de arqueólogo, ni ha frecuentado los despachos del profesionalismo, y sus campañas de trabajo de campo no han tenido más financiación que la que ha salido de su bolsillo. Pocos de entre los miembros, por lo general ocupadísimos, de tales gremios reconocerían su nombre ni le habrán citado en sus bibliografías. Ni siquiera deben temer que Elías, nativo de Villaespasa y habitante hoy, siempre que puede, del pueblo de Peñahorada, les vaya a quitar su sillón, como hizo en alguna versión del cuento el pastor con el abad, porque, para convertirse en el gran etnógrafo que ha tenido y tiene la provincia de Burgos, a Elías no le ha hecho falta, ni hubiera podido ni querido, hacer algo así.

El caso es que Elías Rubio ha ido construyendo con la libertad y el sosiego que los profesionales agobiados siempre con plazos y papeleos no se pueden permitir una obra etnográfica distinta y original. Fruto de toda una larga vida contemplando primero la vida ensimismada de la posguerra en la que nació, y después la ruina feroz de los pueblos de su provincia burgalesa, y también de algunos de los últimos refugios de la tradición por ejemplo, del último alfar de la calle Alfareros, cuyos moldes de escayola vertidos entre los escombros él contribuyó, con nocturnidad y alevosía, a rescatar - de la propia capital.

Así escribe - $-\mathrm{y}$ denuncia — en una de las páginas de este libro:

No hace tanto tiempo que la Torre del Abad [del monasterio de Rioseco], por cuyo arco se accedía al monasterio, todavía se encontraba en pie y era el distintivo más llamativo de las ruinas. Fue a principios de los noventa del pasado siglo cuando se vino abajo. María Ángeles vivió así aquel momento: «la torre se cayó un 14 de agosto; me acuerdo porque era el cumpleaños de mi marido. Estábamos comiendo...». 
La etnografía de Elías Rubio se ha hecho a fuerza de caminar sin prisas y de volver año tras año y década tras década por montes, páramos y caminos de cabras — o de ovejas, más bien - ; de descender a cuevas, descubrir - y luchar por las preservación de - castros y eremitorios rupestres, sacar decenas de miles de fotografías de piedras, árboles, caminos, cañadas, descampados, aldeas, ermitas, cuevas, restos de chamizos, herrerías, tejeras (tejeras de las que llevaron a los pueblos de Burgos y a tantos otros lugares de España los teyerus asturianos de Llanes), turberas, salinas, ferrerías, hornilleras (colmenares), alfares, palomares, molinos en ruinas, escuelas abandonadas, fábricas quemadas, cines cerrados... Y a fuerza, sobre todo, de conversar, registrar, transcribir y fotografiar con respeto y escrúpulo las palabras y las caras, gestos, casas, talleres y entornos de sus paisanos, a los que él en vez de llamar informantes llama amigos.

De hecho, las voces en primera persona y los semblantes de los últimos mineros, ferreros, molineros, muleros, leñadores, serenos y zahoríes de péndulo - de péndulo para descubrir aguas y de péndulo para detectar enfermedades - que han vivido en la provincia de Burgos donde podrán ser encontrados es en esta etnografía de Elías Rubio, y no en ninguna otra.

Una parte de los saberes, testimonios y documentos acumulados la había ido publicando, autoeditando y distribuyendo él casi siempre, en una larga serie de libros cuyo goteo no comenzó pero sí cobró vigor con Monjes y eremitas: santuarios de roca del sureste de Burgos (1986). Arquitectura del agua: fuentes de la provincia de Burgos (1994) y La linterna mágica: un siglo de cinematógrafo en Burgos (1995) son documentadísimos ejercicios de etnohistoria. Aunque estos y todos sus demás libros son únicos e insustituibles, un hito que creo muy destacado, desde el punto de vista de la elaboración y de la sistematicidad etnográfica — prueba, además, de que él llegó adonde no lo ha hecho ningún profesional - es Pasiegos de Burgos: los últimos trashumantes (2005): una monografía científica densa e irreprochable, que reivindica una población y una cultura apartadísimas, que habían pasado desapercibidas entre la oficialidad académica.

Desde el año 2009, Elías mantiene un blog, Memorias de Burgos, que ahora, en diciembre de 2017, tiene 610 entradas, y que en 2015, cuando el autor decidió hacer la demasiado breve - selección que ha quedado reflejada en este libro, tenía más de quinientas. Las entradas de su blog, y esta antología impresa, que por un lado deslumbra y por otro deja cierto regusto de insatisfacción, porque se echan en falta artículos memorables que se quedaron en el blog, se ajustan a una poética y a una retórica en las que el autor se mueve como pez en el agua.

Tales poética y retórica comprenden el despliegue de una prosa fina y lírica vertida en entradas monográficas de pocas páginas, de extensión similar a la que podría tener una crónica periodística algo generosa; la descripción del presente del lugar y la caracterización bien documentada y sin prolijidad de su pasado; el subrayado del componente rural y tradicional, pero también de los efectos que han obrado en estos lugares la modernidad, la industrialización, la desindustrialización, la construcción y el abandono de vías de comunicación — desde la arriería al ferrocarril—, la emigración, el retorno de los emigrantes enriquecidos — memorables las páginas dedicadas a los indianos y a sus obras - o envejecidos a sus lugares de origen, la especulación y los desafueros urbanísticos; la atención al paisaje humano y la entrevista personal con los nativos y su transcripción literal o su síntesis como fuente básica de documentación; la búsqueda, muy en particular, del testimonio de los más viejos, en tanto que depositarios más legítimos de la memoria; la atención, también muy singular, a la descripción de artes, 
profesiones y ocupaciones hoy perdidos, en la voz de las últimas personas que llegaron a ejercerlos o a conocer a sus últimos oficiantes; la toma en cuenta de la arqueología, la epigrafía, la paleontología, la geología, la espeleología, la historia, la historia del arte, la arquitectura, la literatura, la literatura oral, a la hora de identificar, describir y analizar lugares, paisajes, monumentos, ruinas, palabras; el señalamiento y la denuncia, con propuestas muy razonables para contribuir a su preservación, de los peligros que amenazan la conservación de lugares y monumentos en riesgo; y la interpolación de fotografías de gran calidad documental y artística, hechas y seleccionadas por quien ha contemplado esos paisajes y ruinas muchas veces y ha elegido la perspectiva, el momento, la luz y las sombras más adecuados. Quien se asome a las páginas de este libro encontrará, por cierto, las fotos en blanco y negro; y quien busque en el blog, las hallará en color.

En fin, que estas Memorias de Burgos, edificadas, como reza su subtítulo, en el tiempo y el espacio casi inasibles - para quien no quiera y no sepa acercarse a ellos, que es la gran mayoría de la gente y de los estudiosos- que media Entre la tierra y la voz, son el fruto último (por el momento) de la pasión de un etnógrafo burgalés empeñado, muy en contra de la corriente, en salir un día tras otro al campo - y a su ciudad - con el fin de escuchar, ver, aprender, registrar y compartir, y no con el de subirse a ningún estrado para a-leccionar. Son, sin duda, un monumento a lo que los antropólogos llaman observación participante, es decir, a la captura de datos continua y demorada, hecha mientras se vive por largo tiempo en el seno, y no mientras se visita por unas horas o por unos días o meses la comunidad estudiada.

Elías Rubio, con sus cuadernos, grabadoras y cámaras fotográficas en ristre, ha llegado a ser una figura más dentro de ese paisaje. Ha recorrido todos y cada uno de los pueblos - y también de los despoblados de los que ha tenido noticia — burgaleses, subido a sus campanarios, torres y conjuraderos, visitado sus iglesias y ermitas y bajado a sus cuevas y ríos subterráneos, y ha conversado con sus habitantes y puede que con sus fantasmas. En el Centro de Usos Múltiples de Jaramillo de la Fuente, al lado de la fastuosa iglesia románica, ha instalado un Mapa de las Tierras de Burgos hecho con tierra procedente de todos y cada uno de los pueblos de la provincia; y allí al lado, sobre la mezcla de las tierras que sobraron, ha levantado el Árbol de la Provincia.

No tenemos ninguna certeza de que todo esto responda a la aplicación de un método etnográfico ortodoxo, pero sí de que, sin su esfuerzo, su provincia sería mucho más ignorante de sí misma que lo que hoy es. Tampoco sabemos si su compromiso con la preservación del patrimonio ecológico, artístico y etnográfico de Burgos podrá ir más allá de la línea de lo testimonial, porque tiene que ser difícil detener el desmoronamiento literal — de toda una constelación de pueblos cuando los políticos que deberían velar y que son los únicos que podrían poner los medios efectivos para ello no han levantado siquiera un museo etnográfico provincial que haga inventarios, recupere, conserve, investigue, difunda y haga políticas educativas sobre la base del patrimonio incalculable que se está perdiendo.

Estas Memorias de Burgos: entre la tierra y la voz llevan una presentación breve y sutil de Josemi Lorenzo Arribas, otro etnohistoriador polifacético e indispensable, cuya ciencia, que brota de la rudeza del campo, la piedra y el archivo, se construye igualmente de abajo arriba. Y termina casi con un «Rincón lírico» en que Elías Rubio da rienda un poco más suelta a su alma de poeta, o, si se quiere, de poeta en prosa; que no en vano es autor de un volumen de cuentos de ficción, El año de la gripe y otros relatos burgaleses (2005) escrito en una de las más finas prosas costumbristas que se han conocido en 
España. El conclusivo «Índice de lugares» nos confirma que, aunque este libro es más que eso, sí que estamos ante una monografía etnográfica con todas las de la ley.

José Manuel Pedrosa

(Universidad de Alcalá)

임 